\title{
O significado da música para puérperas acerca da vivência no pré-parto
}

\section{The meaning of music for puerperal women regarding the prepartum experience El significado de la música para puérperas acerca de la vivencia pre-parto}

Recebido: 29/09/2018

Aprovado: 04/04/2019

Publicado: 01/07/2019

\author{
Patrícia Costa dos Santos da Silva ${ }^{1}$ \\ Cristiane Matos Nogueira ${ }^{2}$ \\ Lívia Ferreira Oliveira ${ }^{3}$ \\ Efigênia Aparecida Maciel de Freitas ${ }^{4}$
}

O objetivo deste estudo foi conhecer o significado da música para puérperas acerca da vivência do trabalho de parto. Trata-se de estudo de abordagem qualitativa, descritiva e exploratória, realizado em um hospital situado na região do Triângulo Mineiro com oito mulheres, que participaram de encontros musicais durante o período de trabalho de parto. A coleta de dados ocorreu após o parto, por meio da técnica de entrevista semiestruturada e os dados foram organizados pela análise de conteúdo temática. Três unidades categóricas foram construídas: a influência da música na redução álgica; a utilização da música na redução de ansiedade e estresse relacionados ao parto; e a música como estratégia de acolhimento. 0 significado da música na perspectiva destas mulheres constituiu-se num recurso terapêutico que minimiza a dor no trabalho de parto, alivia a ansiedade e o estresse gerado nesse momento ímpar na vida, além de promover um ambiente de acolhimento.

Descritores: Música; Musicoterapia; Enfermagem; Humanização da assistência.

The objective of this study was to know the meaning of music for puerperal women during labor. This is a descriptive and exploratory study with a qualitative approach, conducted in a hospital located in the Triângulo Mineiro region with eight women who participated in musical encounters during the labor period. Data was collected after birth using a semi-structured interview technique and organized through thematic content analysis. Three categorical units were found: the influence of music on pain reduction; the use of music in the reduction of anxiety and stress related to labor; and music as a strategy of embracement. The meaning of music from the perspective of these women was that of a therapeutic resource that minimizes pain in labor, relieves the anxiety and stress generated at this unique moment in life, and fosters a welcoming environment.

Descriptors: Music; Music therapy; Nursing; Humanization of assistance.

El objetivo de este estudio fue conocer el significado de la música para puérperas acerca de la vivencia del trabajo de parto. Se trata de un estudio de abordaje cualitativo, descriptivo y exploratorio, realizado en un hospital situado en la región del Triângulo Mineiro con ocho mujeres que participaron de encuentros musicales durante el periodo de trabajo de parto. La colecta de datos ocurrió después del parto, por medio de la técnica de entrevista semiestructurada y los datos fueron organizados por el análisis de contenido temático. Tres unidades categóricas fueron construidas: la influencia de la música en la reducción del dolor; la utilización de la música en la reducción de ansiedad y estrés relacionados al parto; y la música como estrategia de acogimiento. El significado de la música en la perspectiva de estas mujeres se constituye en un recurso terapéutico que minimiza el dolor en el trabajo de parto, alivia la ansiedad y el estrés generado en este momento único de la vida, además de promover un ambiente de acogimiento.

Descriptores: Música; Musicoterapia; Enfermería; Humanización de la atención.

1. Enfermeira. Especialista em Terapia Intensiva. Mestre em Ciências da Saúde. Doutora em Ciências. Pós Doutora em Enfermagem. Professora Adjunta da Universidade Federal de Uberlândia (UFU), Uberlândia, MG, Brasil. 0RCID: 0000-0001-9643-1865 E-mail: patriciacsilva@usp.br

2. Acadêmica do Curso de Graduação em Enfermagem, UFU, Uberlândia, MG, Brasil. ORCID: 0000-0003-3430-3571 E-mail: cristianematosnogueira@gmail.com

3. Enfermeira. Especialista em Enfermagem do Trabalho. Mestre em Patologia. Doutora em Ciências da Saúde. Professora Adjunta, UFU, Uberlândia, MG, Brasil. ORCID: 0000-0003-1978-7889 E-mail: liviaenfermg@yahoo.com.br

4. Enfermeira. Especialista em Enfermagem Obstétrica. Especialista em Saúde Pública. Mestre em Ciências da Saúde. Doutora em Enfermagem Psiquiátrica. Professora da Faculdade de Medicina da UFU, Uberlândia, MG, Brasil. ORCID: 0000-0003-4434-7762 E-mail. efigeniaufu@gmail.com 


\section{INTRODUÇÃO}

$\mathbf{N}$ os hospitais e nas maternidades, o parto é um evento frequente. Apesar disso, cada mulher deve receber um atendimento individualizado, tendo em vista que o parto é vivenciado de forma subjetiva por cada mulher. Nesse sentido, a assistência e o cuidado nesse período devem ser oferecidos de forma holística e humanizada para cada parturiente ${ }^{1}$.

No ambiente hospitalar, observa-se o predomínio de um modelo de assistência pautado na tecnologia e na medicalização. Porém, a enfermeira obstétrica trabalha sob uma óptica holística e humanizada com relação ao parto e ao nascimento e tem se mostrado um elemento importante na desmedicalização do parto e do nascimento. Isso ocorre porque há uma substituição de práticas e intervenções consideradas rotineiras, mas que possuem uma interferência prejudicial no processo de parturição. A substituição por outras práticas e cuidados, que não interferem no desenvolvimento fisiológico do trabalho de parto e parto, proporciona uma participação mais ativa da parturiente e de seus acompanhantes ${ }^{2}$.

Nesse cenário, a enfermagem apresenta uma parcela contributiva para a execução das políticas públicas de Humanização do Parto e Nascimento do Ministério da Saúde do Brasil e atendendo às recomendações proferidas pela Organização Mundial de Saúde, com o intuito de aumentar o parto vaginal normal e a diminuição da morbimortalidade materna, perinatal e neonatal ${ }^{3}$.

Dentre as práticas para a humanização do pré-parto, há a aplicação da música, que tem sido um elemento capaz de aliviar as dores durante as contrações, auxiliar na diminuição da tensão e do medo, na ambientalização da parturiente no hospital, além de promover um estímulo pela busca pela espiritualidade, sendo um diferencial para a paciente 4 .

Para ampliar a compreensão sobre o significado da música para mulheres que vivenciam o trabalho de parto, faz-se necessária a realização de pesquisas que possam elucidar como a música é vista pelas mulheres nesse período, que implica naturalmente em maior vulnerabilidade e modificações fisiológicas. Assim, este estudo tem como objetivo compreender o significado da música para puérperas acerca da vivência do trabalho de parto.

\section{MÉTODO}

Estudo qualitativo, descritivo, exploratório, que foi realizado no Centro Obstétrico de um Hospital Público de ensino, de média e alta complexidade, localizado no interior de Minas Gerais. Este estudo recebeu aprovação do Comitê de Ética e Pesquisa da Universidade Federal de Uberlândia, obtendo o número de parecer $\mathrm{n}$ - 1.833.534. Os participantes foram orientados quanto ao tema, ao objetivo da pesquisa e com relação ao sigilo das informações coletadas, que podem ser utilizadas para fins científicos, realizando a leitura e a assinatura do Termo de Consentimento Livre e Esclarecido. Esse hospital foi escolhido por possuir grupos de voluntários ligados a atividades extensionistas que executam semanalmente encontros musicais.

A coleta de dados foi feita por meio da técnica de entrevista, no período de junho a agosto de 2017 e de abril a maio de 2018, utilizando-se questões para caracterização socioeconômica do grupo estudado (estado civil, estado conjugal, escolaridade e renda familiar) e um roteiro de entrevista semiestruturada. Tal roteiro possuía questões norteadoras (conhecimento das atividades desenvolvidas pelo grupo de música; o que sentiu e qual foi o significado da música) e foi construído pelos próprios pesquisadores.

Os participantes do estudo foram identificados por nomes femininos e bíblicos, visando assim manter em sigilo a identidade e o anonimato.

Por intermédio de convite verbal, foram abordadas participantes que estavam no período pré-parto e internadas no Centro Obstétrico, e, destas, foram recrutadas aquelas que atendiam aos critérios de inclusão e 
exclusão, compondo assim a amostra do presente estudo. Foi possível verificar que as informações obtidas não apresentavam dados novos por meio do critério de saturação dos dados 4 .

Os discursos obtidos nas entrevistas foram registrados e gravados através de um aplicativo de voz da Samsung-Galaxy Ace GTS5830B®, sendo transcritos na íntegra e analisados segundo a modalidade temática proposta por Minayo ${ }^{5}$, determinando-se as Unidades de Significados dos relatos e a categorização dos dados.

A entrevista ocorreu nas primeiras 24 horas após o parto, uma única vez, e durou aproximadamente 40 minutos para cada participante da pesquisa. Dentre os critérios de inclusão utilizados, cabe mencionar: participantes com mais de 18 anos de idade, que participaram de pelo menos um encontro musical desenvolvido pelo grupo de voluntários do hospital durante sua vivência do trabalho de parto.

Os critérios de exclusão foram: puérperas que não responderam o questionário de dados socioeconômicos completamente e aquelas que apresentaram baixa capacidade cognitiva de acordo com o Mini-Exame do Estado Mental (MEEM).

0 MEEM é um instrumento constituído de 30 questões, com uma pontuação que vai de zero a 30 , sendo que zero equivale a um maior grau de comprometimento cognitivo e 30 a melhor capacidade cognitiva. 0 ponto de corte deverá ser ajustado de acordo com os anos de escolaridade, sendo que: para pessoas sem escolaridade, 13 pontos; para pessoas com um a oito anos de escolaridade, 18 pontos; e, para aqueles com mais de oito anos de escolaridade, 26 pontos ${ }^{7}$.

As etapas que compõem a Análise de Conteúdo - Modalidade Temática proposta por Minayo - foram: 1) pré-análise; 2) exploração do material; e 3) tratamento dos resultados e interpretação ${ }^{6}$. Essas foram as etapas utilizadas para análise do material coletado.

\section{RESULTADOS}

Foram abordadas 15 parturientes e recrutadas 8 puérperas. $\mathrm{Na}$ avaliação socioeconômica observou-se predomínio de: renda familiar de um a dois salários mínimos e três salários, situação conjugal de casada ou em união estável e escolaridade de ensino médio completo. Seis puérperas tiveram gestação de baixo risco, seguidas de duas com alto risco; cinco com parto cesárea e três com parto normal.

Após a análise das transcrições dos dados gravados, foram construídas três categorias: A influência da música na redução álgica; $A$ utilização da música na redução de ansiedade e estresse relacionados ao parto; e, $A$ música como estratégia de acolhimento.

\section{A influência da música na redução álgica}

De acordo com as pesquisadas, a música atua de modo terapêutico na redução da dor de pacientes durante o período de parto, sendo essencial a utilização desse recurso na prática assistencial, conforme observa-se nas seguintes falas:

"[...] além de ajudar a relaxar na questão da dor que está sentindo [...] ameniza a situação pela qual a gente está passando, pelo momento difícil que são as contrações com dores". (Maria)

"A música ajudou pelos menos a minimizar a dor e a gente vai cantando e vai se alegrando mais um pouco." (Maria)

$\mathrm{Na}$ fala de Talita percebe-se que o trabalho de parto está desvinculado da emoção em decorrência da intensidade da dor, mas a partir do momento em que entra em cena a música, existe uma melhora desse quadro, inclusive se comparado ao de seu outro parto, no qual não houve a inclusão da música:

"[...] na verdade a gente não tem muita emoção porque é tanta dor, ontem foi melhor do que do meu outro filho, [...] teve música [...]. (Talita)

A utilização da música na redução de ansiedade e estresse relacionados ao parto

Para as pesquisadas a música possibilitou a redução da ansiedade e do estresse:

"[...] eu só queria ganhar neném, eu já estava ansiosa pra ganhar neném, e foi boa a música, tranquilizou bastante, pois a gente estava esperando [...]. (Rute)

"Tirou um pouco da ansiedade, tirou um pouco daquele pensamento de descer; parto... é acalmou bastante [...]. (Rute) 
"Sim, eu estava preocupada porque eles estavam pensando em virar ele, só que avisaram que podia ter o risco de entrar em cesárea com urgência, mas depois (da música) eu fiquei bem tranquila, foi bem tranquilizante". (Débora) "(A música) me ajudou bastante, fiquei calma, tranquila, trouxe tranquilidade para mim e para ele também (o acompanhante), saiu da tensão, trouxe mais amor, porque é tenso lá dentro, é mais aconchegante, traz tranquilidade para o coração, porque nossa é complicado". (Rute)

$\mathrm{Na}$ visão de Ana o trabalho de parto produz estresse e a música produz um relaxamento e uma emoção interior, inclusive se referindo ao nascimento do seu bebê:

"[...] emocionalmente, foi bem lá dentro mesmo, também estava bem com sono, aliviou bastante a questão do estresse, foi bem relaxante e eu gosto de música, e a bebê também curte... não é bebê. (Ana)

\section{A música como estratégia de acolhimento}

A música parece atuar de forma acolhedora durante o período de parto, o que pode ser evidenciado na fala da parturiente quando questionada de que forma vivenciou a experiência com a música naquele momento, trazendo à tona uma questão que acontece com várias mulheres: o fato de estarem sozinhas, sem um acompanhante. A música, para ela, proporciona um conforto, ou seja, a faz sentirse acolhida:

"Eu acho que está perfeito, vocês chegam lá colocam as músicas, conversa, dá atenção, pergunta, tem mulheres que não estão acompanhadas, não tem acompanhantes, estão sozinhas, ajuda bastante o projeto, as músicas e a companhia de vocês". (Rute)

\section{DISCUSSÃO}

0 presente estudo, que teve como objetivo conhecer o significado da música para as gestantes durante o trabalho de parto, permitiu a construção de três categorias que desvelam a importância da música no cenário obstétrico.
Com
relação
aos
dados

sociodemográficos evidencia-se que a maioria das mulheres que participaram deste estudo tiveram parto cesárea. Um estudo ${ }^{8}$ mostrou que o principal motivo para a escolha da cesariana ainda é o medo da dor do parto e a realização de laqueadura tubária ${ }^{8}$.

$\mathrm{Na}$ primeira categoria construída observa-se, nas falas das parturientes, que a música representa um elemento que provoca relaxamento e alívio das contrações uterinas. Tais dados estão em consonância com estudos que apontam a música como um método terapêutico, não farmacológico, que influencia na redução álgica ${ }^{4,9,10}$.

A sensação de relaxamento produzida pela música no decorrer do trabalho de parto torna o momento das contrações uterinas mais suportável, devido ao estímulo agradável em diferentes áreas cerebrais, o que ativa regiões ligadas à parte emocional e do circuito de recompensas, reduzindo significativamente o estresse no decorrer do parto. Além disso, a música é capaz de desencadear a liberação de endorfina no sangue, um neuropeptídio produzido naturalmente pela hipófise que atua de maneira eficaz na redução da dor ${ }^{4,9,10}$.

Mulheres no primeiro estágio do parto e que receberam estimulação musical tiveram o início de um parto natural e com menos uso de medicação do que aquelas que não foram estimuladas musicalmente ${ }^{11}$. Além disso, a música no momento do parto é um instrumento de relaxamento e minimização de medo, de tensão e de dor, podendo limitar o sofrimento e potencializar a sensação de bem-estar ${ }^{12-13}$.

Em outro estudo, os resultados sugerem que a música, quando utilizada no transoperatório, promoveu uma sensação de bem-estar, relaxamento e até mesmo a redução da dor. Além disso, a música faz com que o ser humano desenvolva sensações e sentimentos de alegria, o que reduz ou mesmo elimina a tensão característica dos períodos pré e transoperatório. Nessa perspectiva, a música se torna uma ferramenta de tecnologia simples e inovadora que vem sendo, com o passar dos anos, utilizada em diversos serviços de saúde ${ }^{14}$.

Além da redução álgica relatada pelas parturientes, pode-se observar, nas entrevistas, que a música produz uma redução na ansiedade e no estresse relacionados ao parto, permitindo que as parturientes expressem suas preocupações com o processo do trabalho de parto, promovendo a expressão de sensações e a participação ativa da mulher no processo de nascimento. 0 momento do trabalho de parto gera estresse. Nesse sentido, a música pode 
minimizar a tensão muscular quando apresenta timbres suaves, ritmos lentos e combinações harmoniosas ${ }^{13}$.

Em relação à categoria $A$ música como estratégia de acolhimento, nota-se que a música contribui em proporcionar tranquilidade, por permitir que as parturientes se sintam acolhidas, pois a música complementa a ausência de familiares no momento do parto. 0 acolhimento, enquanto diretriz essencial do modelo assistencial estabelecido pelo Sistema Único de Saúde (SUS), favorece o fortalecimento das relações, sendo que a escuta e a atenção são importantes para que o serviço de saúde ofereça resolutividade para as demandas dos usuários ${ }^{15}$.

0 acolhimento compreende um momento oportuno para que a equipe multiprofissional estabeleça o vínculo, a escuta terapêutica e a integralidade, almejando, assim, atender às expectativas das parturientes e de suas famílias, esclarecendo as dúvidas relacionadas à gestação e ao parto. Isso torna o acolhimento uma ferramenta que facilita a relação das parturientes com os profissionais, evitando, assim, situações de estresse e angústia para as mulheres e suas famílias.

Estudos apontam a música como um instrumento que contribui para o fortalecimento de vínculos, uma vez que estimula a comunicação entre o paciente, a família e a equipe multiprofissional, o que conduz a uma assistência holística e humanizada ${ }^{15,16 .}$

\section{CONCLUSÃO}

O estudo permitiu conhecer o significado da música durante o trabalho de parto na visão das parturientes, por meio da construção de três categorias: a influência da música na redução álgica; a utilização da música na redução da ansiedade e estresse relacionados ao parto e a música como estratégia de acolhimento.

Para que a equipe multiprofissional possa ofertar um parto e nascimento humanizados, faz-se necessária a utilização de técnicas não farmacológicas, como a música, que permite a criação de um cenário que busque um vínculo e um ambiente no qual predomine o acolhimento e que respeite os direitos das mulheres.

Além disso, o estudo trouxe importantes reflexões sobre o cuidado holístico oferecido à parturiente, trazendo formas de cuidar que contribuam para o seu protagonismo. Esperase, ao mesmo tempo, que o estudo seja um instrumento, não apenas para os enfermeiros, mas para todos os profissionais de saúde, no sentido de formular estratégias para a humanização do cuidado à parturiente e sua família.

Por outro lado, é importante salientar que esta pesquisa foi desenvolvida com parturientes de uma instituição específica, o que pode representar uma limitação do estudo, não possibilitando uma generalização mais ampla dos resultados. Assim, novos estudos para se conhecer a visão de outras parturientes, em diferentes instituições e contextos, com o envolvimento de um número maior de mulheres, poderá ampliar a visão e compreender diferentes aspectos acerca da temática em questão.

\section{REFERÊNCIAS}

1. Martins GF, Vieira LG. Práticas integrativas e complementares para o bem-estar da gestante. Rev Bras Ciênc Vida. [Internet]. 2018 [citado em 18 ago 2018]; 6(Esp):1-4. Disponível em:

http://jornal.faculdadecienciasdavida.com.br/i ndex.php/RBCV/article/view/772

2. Reis CSC, Souza DOM, Nogueira MFH, Progianti JM, Vargens OMC. Análise de partos acompanhados por enfermeiras obstétricas na perspectiva da humanização do parto e nascimento. Rev Pesqui Cuid Fund. (Online). [Internet]. 2016 [citado em 18 ago 2018]; 8(4):4972-9. DOI: http://dx.doi.org/10.9789/2175-

5361.2016.v8i4.4972-4979

3. Santos HFL, Araújo MM. Políticas de humanização ao pré-natal e parto: uma revisão de literatura. Rev Cient FacMais. [Internet]. 2016 [citado em 05 abr 2018]; 6(2):55-64. Disponível 
http://revistacientifica.facmais.com.br/wpcontent/uploads/2016/07/Artigo-6-

POL\%C3\%8DTICAS-DE-

HUMANIZA\%C3\%87\%C3\%830-AO-

PR\%C3\%89-NATAL-E-PARTO.pdf

4. Tabarro CS, Campos LB, Galli NO, Novo NF, Pereira VM. Efeito da música no trabalho de parto e no recém-nascido. Rev Esc Enferm USP. [Internet]. 2010 [citado em 05 abr 2018]; 44(2):445-52. Disponível em: http://www.scielo.br/pdf/reeusp/v44n2/29.p df

5. Costa MCS, Rossi LA, Lopes LM, Cioffi CL. Significados de qualidade de vida: análise interpretativa baseada na experiência de pessoas em reabilitação de queimaduras. Rev Latinoam Enferm. [Internet]. 2008 [citado em 15 mar 2018]; 16(2):252-9. Disponível em: http://www.scielo.br/pdf/rlae/v16n2/pt_13.p df

6. Minayo MCS. O desafio do conhecimento: pesquisa qualitativa em saúde. 14ed. São Paulo: Hucitec; 2014.

7. Trindade APNT, Barboza MA, Oliveira FB, Borges APO. Repercussão do declínio cognitivo na capacidade funcional em idosos institucionalizados e não institucionalizados. Fisioter Mov. [Internet]. 2013 [citado em 15 mar 2018]; 26(2):281-9. Disponível em: http://www.scielo.br/pdf/fm/v26n2/05.pdf

8. Domingues RMSM, Dias MAB, NakamuraPereira M, Torres JA, D'Orsi E, Pereira APE, et al. Processo de decisão pelo tipo de parto no Brasil: da preferência inicial das mulheres à via de parto final. Cad Saúde Pública. [Internet]. 2014 [citado em 05 abr 2018]; 30(Sup):S101-S116. Disponível http://www.scielo.br/pdf/csp/v30s1/0102311X-csp-30-s1-0101.pdf

9. Araújo TC, Pereira A, Sampaio ES, Araújo MSS. Uso da música nos diversos cenários do cuidado: revisão integrativa. Rev Baiana Enferm. [Internet]. 2014 [citado em 05 abr 2018]; 28(1):96-106. Disponível em: https://portalseer.ufba.br/index.php/enferma gem/article/viewArticle/6967

10. Araújo ASC, Correia AM, Rodrigues DP, Lima LM, Gonçalves SS, Viana APS. Non- pharmacological methods in home birth. J Nurs UFPE on line. [Internet]. 2018 [citado em 15 mar 2018]; 12(4):1091-6. DOI: http//doi.org/10.5205/1981-8963v12i4a230120p1091-1096-2018

11. Garcia Gonçaléz J, Ventura Miranda MI, Requena Mullor M, Parron Carreño T, Alarcón Rodriguez R. Effects of prenatal music stimulation on state/trait anxiety in full-term pregnancy and its influence on childbirth: a randomized controlled trial. J Matern Fetal Neonatal Med. [Internet]. 2017 [citado em 05 abr 2018]; 31(8):1058-65. Disponível em: https://www.ncbi.nlm.nih.gov/pubmed/2828 7005

12. Dzymalski DM, Tsen LC, Palanisamy A, Zhou J, Huang CC, Kodali BS. A randomized controlled trial of music use during epidural catheter placement on laboring parturient anxiety, pain, and satisfaction. Anesth Analg. 2017; 124(2):542-7.

13. Nunes-Silva M, Moreira LC, Moraes GRJ, Rosa GT, Marra CAS. A música para indução de relaxamento na Terapia de Integração Pessoal pela Abordagem Direta do InconscienteADI/TIP. Contextos Clín. [Internet]. 2012 [citado em 15 mar 2018]; 5(2):88-99. Disponível em: http://pepsic.bvsalud.org/pdf/cclin/v5n2/v5n 2a04.pdf

14. Caitano JSO, Azevedo EB, Costa LDFP, Soares CCD, Aguiar PV, Ferreira Filha MO. Música durante o transoperatório: concepção de profissionais e pacientes. Rev Bras Pesqui Saúde. [Internet]. 2014 [citado em 15 mar 2018]; 16(2):76-83. Disponível em: http://periodicos.ufes.br/RBPS/article/view/ 9289

15. Brehmer LSF, Verdi M. Acolhimento na Atenção Básica: reflexões éticas sobre a Atenção à Saúde dos usuários. Ciênc Saúde Coletiva. [Internet]. 2010 [citado em 18 abr 2018]; 15(3):3569-78. Disponível em: http://www.scielo.br/pdf/csc/v15s3/v15s3a3 2.pdf

16. Silva LAGP, Baran FDP, Mercês NNA. A música no cuidado às crianças e adolescentes com câncer: revisão integrativa. Texto \& 
Contexto Enferm. [Internet]. 2016 [citado em 05 abr 2018]; 25(4):1-10. Disponível em: http://www.scielo.br/pdf/tce/v25n4/pt_0104 -0707-tce-25-04-1720015.pdf

CONTRIBUIÇÕES
Todas as autoras tiveram iguais
contribuições, quais sejam: desenho do
estudo, coleta de dados, análise dos dados,
redação e revisão.

\section{Como citar (Vancouver)}

Silva PCS, Nogueira CM, Oliveira LF, Freitas EAM. O significado da música para puérperas acerca da vivência no pré-parto. REFACS [Internet]. 2019 [citado em inserir dia, mês e ano de acesso]; 7(3): 331-337. Disponível em: inserir link de acesso. DOI: inserir link do DOI.

\section{Como citar (ABNT)}

SILVA, P. C. S.; NOGUEIRA, C. M.; OLIVEIRA, L. F.; FREITAS, E. A. M. O significado da música para puérperas acerca da vivência no pré-parto. REFACS, Uberaba, MG, v. 7, n. 3, p. 331-337, 2019. Disponível em: inserir link de acesso. Acesso em: inserir dia, mês e ano de acesso. DOI: inserir link do DOI.

\section{Como citar (APA)}

Silva, P.C.S., Nogueira, C.M., Oliveira, L.F. \& Freitas, E.A.M. (2019). 0 significado da música para puérperas acerca da vivência no pré-parto. REFACS, 7(3), 331-337. Recuperado em: inserir dia, mês e ano de acesso de inserir link de acesso. DOI: inserir link do DOI. 